DAS28-CRP $<3.2$ and no swollen joints or an MRI guided T2T strategy based on the same clinical T2T strategy and MRI targeting absence of BME. Patients were followed every 4 months over a 2 year follow-up period. In the MRI T2T arm contrast-enhanced MRI of the dominant hand 2nd-5th metacarpophalangeal joints and wrist was performed ahead of the clinical visit and evaluated for presence/ absence of BME. Treatment was escalated according to a predefined treatment algorithm if target was not reached, starting with increments in csDMARD mono/ combination therapy and then adding biologic DMARDs. The co-primary endpoints were 1) proportion of patients achieving DAS28-CRP remission (DAS28$\mathrm{CRP}<2.6$ ) and 2) proportion of patients with no radiographic progression (change in total Sharp/vdHeijde score $\leq 0) 24$ months from baseline. Secondary outcomes included various clinical, functional, radiographic and MRI variables. Pearson's chi-square statistics and repeated-measures logistic regression models were used to assess primary and secondary outcomes.

Results: Primary and secondary clinical and radiographic outcomes at 24 months are presented in the table 1. 76 patients in the MRI T2T arm and 95 patients in conventional T2T arm completed the study. Of them 64 patients $(85 \%)$ in the MRI T2T arm and 83 patients (88\%) in the conventional T2T arm reached the primary clinical endpoint (chi-square $=0.324, \mathrm{p}=0.569)$ and 49 patients $(66 \%)$ in the MRI T2T arm and $58(62 \%)$ in the conventional T2T arm reached the primary radiographic endpoint (chi-square $=0.265, \mathrm{p}=0.606$ ). ACR/EULAR remission rates, swollen joint count, patient VAS global and HAQ favoured the MRI T2T arm $(\mathrm{p}<0.038)$.

Conclusions: Targeting absence of MRI BME in addition to a conventional T2T strategy in RA patients in clinical remission had no effect on the probability of achieving DAS28-CRP remission or halt radiographic progression. However, more patients achieved ACR/EULAR remission and improvements in physical function when MRI was used for treatment guidance.

Clinicaltrials.gov Identifier: NCT01656278

Disclosure of Interest: None declared

DOI: 10.1136/annrheumdis-2018-eular.1204

\section{OP0019 BARICITINIB IN SYSTEMIC LUPUS ERYTHEMATOSUS (SLE): RESULTS FROM A PHASE 2, RANDOMISED, DOUBLE-BLIND, PLACEBO-CONTROLLED STUDY}

D.J. Wallace $^{1}$, R.A. Furie ${ }^{2}$, Y. Tanaka ${ }^{3}$, K.C. Kalunian ${ }^{4}$, M. Mosca ${ }^{5}$, M.A. Petri ${ }^{6}$, T. Dorner ${ }^{7}$, M.H. Cardiel ${ }^{8}$, I.N. Bruce ${ }^{9}$, E. Gomez ${ }^{10}$, T. Carmack $^{10}$, J.M. Janes ${ }^{10}$, M. D. Linnik ${ }^{10}$, M. Silk ${ }^{10}$, R. Hoffman ${ }^{10} .{ }^{1}$ Cedars-Sinai Medical Center/UCLA, Los Angeles; ${ }^{2}$ Hofstra Northwell School of Medicine, New York, USA; ${ }^{3}$ Univ of Occupational and Environmental Health, Kitakyushu, Japan; ${ }^{4}$ Univ of California at San Diego School of Medicine, La Jolla, USA; ${ }^{5}$ Univ of Pisa, Pisa, Italy; ${ }^{6}$ Johns Hopkins Univ School of Medicine, Baltimore, USA; ${ }^{7}$ Charité Universitätsmedizin Berlin, Berlin, Germany; ${ }^{8}$ Centro de Investigación Clínica de Morelia SC, Morelia, Mexico; ${ }^{9}$ The Univ. of Manchester, Manchester, UK; ${ }^{10}$ Eli Lilly and Company, Indianapolis, USA

Background: Baricitinib (Bari), an oral selective inhibitor of Janus kinase (JAK)1 and JAK2, has been approved for the treatment of RA in the EU and Japan.

Objectives: To report results from a 24 week (wk) global, Phase 2, double-blind, placebo (PBO)-controlled study of Bari in patients with SLE receiving standard therapy.

Methods: Patients with SLE (positive ANA or anti-dsDNA, clinical SLEDAI$2 \mathrm{~K} \geq 4$, arthritis or rash required) receiving stable background SLE therapy were randomised 1:1:1 to PBO, or Bari (2- or $4 \mathrm{mg}$ ) once daily. The primary endpoint was resolution of SLEDAI-2K arthritis or rash at wk 24.

Results: Of 314 patients randomised, $79 \%, 82 \%$, and $83 \%$ completed 24 wks of treatment in $\mathrm{PBO}$, Bari $2 \mathrm{mg}$, and Bari $4 \mathrm{mg}$ groups, respectively. At wk 24, a significantly greater proportion of patients in Bari $4 \mathrm{mg}$ group compared to PBO achieved resolution of SLEDAI-2K arthritis or rash $(67 \%$ vs $53 \%, \mathrm{p}<0.05)$; and SRI-4 response $(64 \%$ vs $48 \%, p<0.05)$. At $W k 24$, the proportion of patients achieving flare reduction (SELENA-SLEDAI Flare Index [SFI]), Lupus Low
Abstract OP0019 - Table 1

\begin{tabular}{lccc}
\hline & $\begin{array}{c}\text { PBO } \\
(\mathbf{n}=\mathbf{1 0 5})\end{array}$ & $\begin{array}{c}\text { Bari } \\
\mathbf{2 ~ m g} \\
(\mathbf{n}=\mathbf{1 0 5})\end{array}$ & $\begin{array}{c}\text { Bari } \\
\mathbf{4} \mathrm{mg} \\
(\mathbf{n}=\mathbf{1 0 4})\end{array}$ \\
\hline Efficacy measure & & Week 24 & $70(67.3)^{*}$ \\
Resolution of arthritis or & $56(53.3)$ & $61(58.1)$ & \\
rash & & & $67(64.4)^{*}$ \\
(SLEDAI-2K) & $50(47.6)$ & $54(51.4)$ & $34(32.7)^{*}$ \\
SRI-4 & $54(51.4)$ & $45(42.9)$ & $6(5.8)$ \\
Flare (SFI, any severity) & $12(11.4)$ & $10(9.5)$ & $40(38.5)^{*}$ \\
Flare (SFI, severe) & $27(25.7)$ & $35(33.3)$ & $-6.86^{*}$ \\
LLDAS & -5.59 & -6.50 & -4.76 \\
DTJC & -4.60 & -4.12 & -2.27 \\
DSJC & -2.80 & -1.66 & $-1.31^{*}$ \\
DCLASI activity score & -0.56 & -1.17 & -1.52 \\
DWorst pain & -1.18 & -1.13 & \\
DWorst fatigue & & Weeks 0-24 & \\
Safety measure & $68(64.8)$ & $75(71.4)$ & $76(73.1)$ \\
TEAEs & $5(4.8)$ & $11(10.5)$ & $10(9.6)$ \\
SAEs & $1(1.0)$ & $2(1.9)$ & $6(5.8)$ \\
Serious infections & 0 & 0 & $1(1.0)$ \\
Deep vein thrombosis & & &
\end{tabular}

Disease Activity State (LLDAS), and tender joint count (TJC) change from baseline were also significantly improved for Bari $4 \mathrm{mg}$ compared to PBO (table 1). No statistically significant differences were observed between Bari $2 \mathrm{mg}$ and PBO in any of the above endpoints. Rates of AEs leading to treatment discontinuation and SAEs were higher for both Bari dose groups compared to PBO. There were no deaths, malignancies, major adverse cardiovascular events, tuberculosis, or serious herpes zoster infections; one SAE of deep vein thrombosis was reported in a patient with risk factors (Bari $4 \mathrm{mg}$ group).

Data are $\mathrm{n}(\%)$ patients, unless otherwise indicated. $\mathrm{D}=$ least squares mean change from baseline. "Includes up to 30 days post treatment. CLASI=Cutaneous Lupus Erythematosus Disease Area and Severity Index; $n=$ number of patients in the analysis population; $n=$ number of patients in the specified category; TEAE=treatment emergent adverse event. ${ }^{*} \mathrm{p} \leq 0.05$.

Conclusions: In patients with SLE receiving standard background therapy, once-daily oral Bari $4 \mathrm{mg}$ was associated with significant clinical improvements compared to PBO and an acceptable benefit/risk profile. These findings support further study of Bari $4 \mathrm{mg}$ as a potential therapy for patients with SLE.

Disclosure of Interest: D. Wallace Consultant for: Eli Lilly and Company, EMD Merck Serono, Pfizer, GSK, R. Furie Consultant for: Eli Lilly and Company, Y. Tanaka Grant/research support from: Mitsubishi-Tanabe, Takeda, Bristol-Myers, Chugai, Astellas, Abbvie, MSD, Daiichi-Sankyo, Pfizer, Kyowa- Kirin, Eisai, Ono, Speakers bureau: Daiichi-Sankyo, Astellas, Pfizer, Mitsubishi-Tanabe, BristolMyers, Chugai, YL Biologics, Eli Lilly, Sanofi, Janssen, UCB, K. Kalunian Consultant for: Eli Lilly and Company, M. Mosca: None declared, M. Petri Consultant for: Eli Lilly and Company, T. Dorner Grant/research support from: Roche/Chugai, Janssen, Sanofi, Consultant for: AbbVie, Celgene, Eli Lilly, Roche, UCB, MSD Pfizer/Hospira, Novartis, Speakers bureau: Amgen, Celgene, Biogen, M. Cardiel Grant/research support from: Pfizer, Gilead, Roche, Janssen, Consultant for: Eli Lilly and Company, Pfizer, Speakers bureau: Eli Lilly and Company, Pfizer, Abbvie, I. Bruce Grant/research support from: Genzyme, GSK, Consultant for: BMS, Eli Lilly and Company, GSK, Astra Zeneca, Speakers bureau: GSK, E. Gomez Shareholder of: Eli Lilly and Company, Employee of: Eli Lilly and Company, T. Carmack Shareholder of: Eli Lilly and Company, Employee of: Eli Lilly and Company, J. Janes Shareholder of: Eli Lilly and Company, Employee of: Eli Lilly and Company, M. Linnik Shareholder of: Eli Lilly and Company, Employee of: Eli Lilly and Company, M. Silk Shareholder of: Eli Lilly and Company, Employee of: Eli Lilly and Company, R. Hoffman Shareholder of: Eli Lilly and Company, Employee of: Eli Lilly and Company

DOI: 10.1136/annrheumdis-2018-eular.1918 